\title{
Development of the Fetal Vermis: New Biometry Reference Data and Comparison of 3 Diagnostic Modalities-3D Ultrasound, 2D Ultrasound, and MR Imaging
}

\author{
(D) E. Katorza, (DE. Bertucci, (D) S. Perlman, (D). Taschini, DR. Ber, (D). Gilboa, (D) V. Mazza, and DR. Achiron
}

\begin{abstract}
BACKGROUND AND PURPOSE: Normal biometry of the fetal posterior fossa rules out most major anomalies of the cerebellum and vermis. Our aim was to provide new reference data of the fetal vermis in 4 biometric parameters by using 3 imaging modalities, 2D ultrasound, 3D ultrasound, and MR imaging, and to assess the relation among these modalities.
\end{abstract}

MATERIALS AND METHODS: A retrospective study was conducted between June 2011 and June 2013. Three different imaging modalities were used to measure vermis biometry: $2 D$ ultrasound, $3 D$ ultrasound, and MR imaging. The vermian parameters evaluated were the maximum superoinferior diameter, maximum anteroposterior diameter, the perimeter, and the surface area. Statistical analysis was performed to calculate centiles for gestational age and to assess the agreement among the 3 imaging modalities.

RESULTS: The number of fetuses in the study group was 193, 172, and 151 for 2D ultrasound, 3D ultrasound, and MR imaging, respectively. The mean and median gestational ages were 29.1 weeks, 29.5 weeks (range, 21-35 weeks); 28.2 weeks, 29.05 weeks (range, 21-35 weeks); and 32.1 weeks, 32.6 weeks (range, 27-35 weeks) for 2D ultrasound, 3D ultrasound, and MR imaging, respectively. In all 3 modalities, the biometric measurements of the vermis have shown a linear growth with gestational age. For all 4 biometric parameters, the lowest results were those measured by MR imaging, while the highest results were measured by 3D ultrasound. The inter- and intraobserver agreement was excellent for all measures and all imaging modalities. Limits of agreement were considered acceptable for clinical purposes for all parameters, with excellent or substantial agreement defined by the intraclass correlation coefficient.

CONCLUSIONS: Imaging technique-specific reference data should be used for the assessment of the fetal vermis in pregnancy.

ABBREVIATIONS: $\mathrm{AP}=$ anteroposterior; $\mathrm{ICC}=$ intraclass correlation coefficient; $\mathrm{SA}=$ surface area; $\mathrm{SI}=$ superoinferior; $\mathrm{US}=$ ultrasound; $\mathrm{VCl}=\mathrm{volume}$ contrast imaging

maging of the fetal posterior fossa is considered a routine part of the fetal sonographic examination. Normal sonographic biometry and normal morphology of the posterior fossa rule out most major anomalies of the fetal cerebellum and vermis. ${ }^{1}$ However, in case of an abnormal posterior fossa, evaluation of the vermian biometry and morphology is of paramount im-

Received August 27, 2015; accepted after revision January 5, 2016.

From the Antenatal Diagnostic Unit (E.K., S.P., R.B., Y.G., R.A.), Department of Obstetrics and Gynecology, Haim Sheba Medical Center, Sackler School of Medicine, Tel Aviv University, Israel; and Prenatal Medicine Unit (E.B., S.T., V.M.), Department of Obstetrics and Gynecology, Modena Hospital, Modena, Italy.

E. Katorza and E. Bertucci contributed equally to this study.

Please address correspondence to Sharon Perlman, MD, Antental Diagnostic Unit, Department of Obstetrics and Gynecology, Sheba Medical Center, Tel HaShomer, Ramat Gan, Israel; e-mail: drsharonperlman@gmail.com; sharoni5@yahoo.com

三 Indicates article with supplemental on-line tables.

http://dx.doi.org/10.3174/ajnr.A4725 portance, considering the wide clinical spectrum of this imaging finding. ${ }^{2}$

Fetal posterior fossa anomalies range from benign asymptomatic conditions to severe abnormalities associated with neurologic impairment. $^{3-6}$ The most frequent of these anomalies, Blakes pouch cyst, vermian hypoplasia, and Dandy-Walker malformation, have a similar imaging appearance ${ }^{7,8}$ but different vermian biometry and, therefore, different prognoses. ${ }^{9}$

Many anomalies of the posterior fossa can be depicted with sonography alone. ${ }^{10}$ Although the standard axial imaging planes may detect most anomalies of the posterior fossa, the diagnosis of the exact type of abnormality might be challenging because a clear visualization of the midsagittal plane is essential. Subtle changes in the morphology of the vermis are hidden by this axial view, and this feature can lead to false-positive diagnoses of vermian pathologies. $^{11,12}$

Our group has proposed using the transabdominal sagittal plane for visualization of the fetal vermis, ${ }^{13}$ while Malinger et $\mathrm{al}^{14}$ 
reported their experience with the transvaginal approach. Vinals et $\mathrm{al}^{15}$ used volume contrast imaging (VCI) on plane $\mathrm{C}$ to construct nomograms for the normal fetal vermis. Our group used this same VCI on plane $\mathrm{C}$ technique to compare normal and abnormal fetal vermis measurements, and we concluded that the $3 \mathrm{D}$ sonographic technique has many advantages in the detection of posterior fossa anomalies. ${ }^{16}$ It allows off-line evaluation and reconstruction of images, even with abnormal angles when the midsagittal plane is difficult to obtain.

MR imaging is a well-known complementary tool in the prenatal diagnosis of fetal brain abnormalities. The challenges described above in achieving a good visualization of the midsagittal

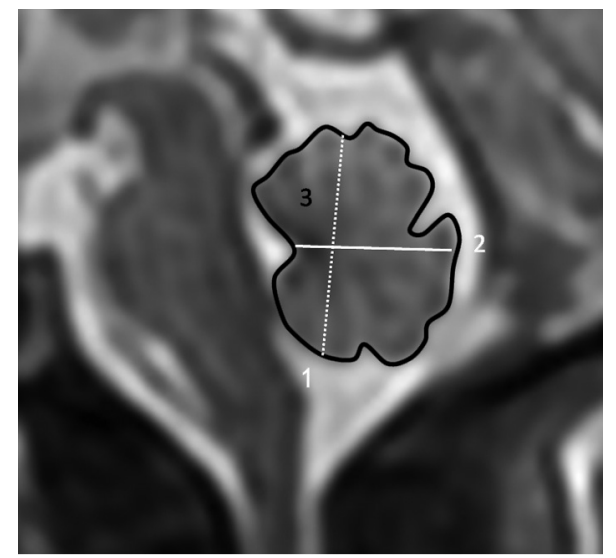

FIG 1. Magnification of the fetal posterior fossa and vermis and demonstration of biometric parameters. 1) Maximum superoinferior diameter. 2) Anteroposterior diameter. 3) Perimeter and surface area.
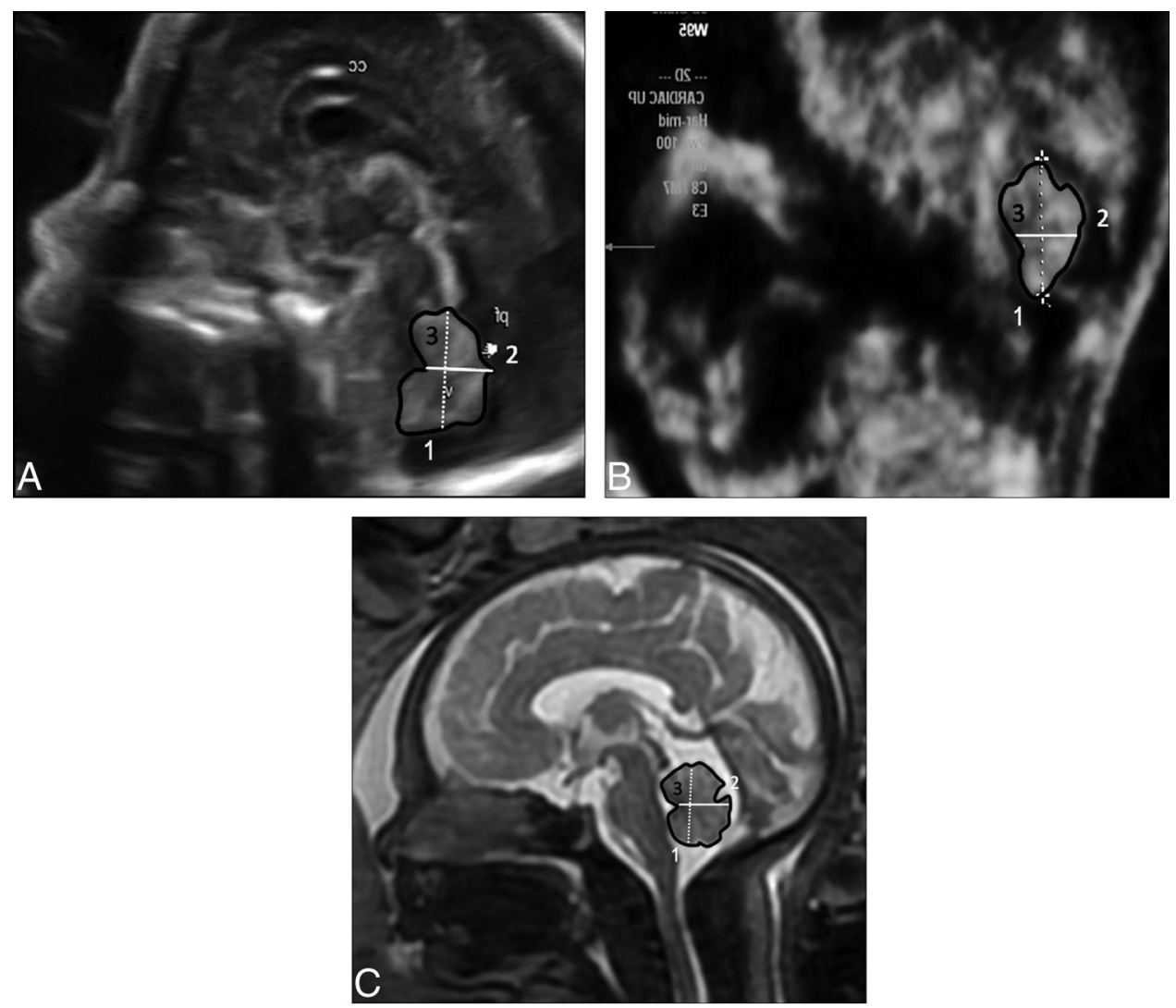

FIG 2. Midsagittal view of the fetal brain demonstrating the vermis. $A, 2 D$ US. $B, 3 D$ US. $C$, MR imaging.

plane in prenatal sonography led to frequent use of this tool to assess, more accurately, the structures of the posterior fossa and improve prenatal diagnosis.

Various nomograms have been developed to establish normal biometric measures of the fetal vermis by using ultrasound (US) or MR imaging. ${ }^{17-19}$ None of these nomograms provided data regarding all 4 vermian biometric parameters. Moreover, there were no comparisons among all 3 imaging modalities. ${ }^{20}$

The aims of our study were the following: to provide normal reference biometric data of the fetal vermis in 4 biometric parameters for 3 imaging modalities, to evaluate the reproducibility of the vermian biometry, and to compare the measurements obtained by $2 \mathrm{D}$ sonography, 3D sonography, and MR imaging.

\section{MATERIALS AND METHODS \\ Population}

A retrospective study was conducted between June 2011 and June 2013.

All sonographic examinations were performed during routine pregnancy follow-up and were in addition to the standard axial views. MR imaging examinations were performed due to increased risk of suspected cerebral pathology, including suspected infectious fetopathy, suspected sonographic cerebral abnormality, positive family history, a previous pregnancy with CNS abnormality, decreased fetal movements, polyhydramnios, and extracranial anomalies such as club foot, cleft lip, and/or palate. However, there was no evidence of intracranial abnormalities.

The inclusion criteria for the 3 groups were the following: singleton pregnancy, good dating, estimated fetal weight within the 10 th to 90 th percentiles, normal obstetric course (no evidence of intrauterine growth restriction or macrosomia or pregnancy-related hypertensive disorders or gestational diabetes mellitus), absence of maternal disease (healthy women without any background illness such as hypercoagulability state, hypertension, diabetes, or other systemic disease), clinically normal fetus at birth (normal Apgar scores at birth, normal neonate physical examination findings), and no known neurologic family history. A detailed sonographic scan was performed to rule out fetal malformations. Only 1 measurement was used for each patient with each gestational week in each imaging technique. 
Table 1: Median, 5th, and 95th percentiles for SI measurements

\begin{tabular}{|c|c|c|c|c|c|c|c|c|c|}
\hline \multirow{3}{*}{$\begin{array}{c}\text { Gestational } \\
\text { Age (wk) }\end{array}$} & \multicolumn{9}{|c|}{ Imaging Modality } \\
\hline & \multicolumn{3}{|c|}{ US 2D } & \multicolumn{3}{|c|}{ US 3D } & \multicolumn{3}{|c|}{ MRI } \\
\hline & $\% 5$ & Median & $\% 95$ & $\% 5$ & Median & $\% 95$ & $\% 5$ & Median & $\% 95$ \\
\hline 21 & 10.69 & 11.95 & 12.57 & 11.10 & 12.30 & 14.60 & & & \\
\hline 22 & 10.42 & 12.72 & 14.40 & 11.50 & 13.60 & 14.90 & & & \\
\hline 23 & 11.71 & 12.79 & 13.84 & 13.00 & 14.40 & 16.50 & & & \\
\hline 24 & 13.33 & 13.79 & 14.82 & 13.40 & 15.35 & 17.50 & & & \\
\hline 25 & 13.85 & 15.17 & 16.66 & 14.50 & 16.00 & 17.80 & & & \\
\hline 26 & 13.75 & 16.09 & 18.45 & 15.60 & 16.80 & 19.50 & & & \\
\hline 27 & 14.05 & 17.07 & 18.78 & 16.70 & 18.70 & 20.20 & 13.30 & 14.13 & 15.05 \\
\hline 28 & 16.08 & 17.09 & 19.72 & 16.30 & 18.80 & 23.80 & 13.66 & 14.58 & 15.73 \\
\hline 29 & 17.29 & 18.72 & 20.33 & 18.10 & 20.00 & 22.20 & 13.25 & 16.02 & 17.54 \\
\hline 30 & 17.83 & 18.56 & 19.62 & 18.40 & 20.50 & 23.60 & 15.77 & 17.38 & 20.76 \\
\hline 31 & 18.03 & 19.34 & 20.75 & 18.10 & 21.30 & 23.80 & 16.16 & 18.02 & 19.34 \\
\hline 32 & 17.68 & 19.33 & 20.59 & 19.00 & 21.40 & 26.60 & 16.75 & 18.67 & 20.12 \\
\hline 33 & 16.78 & 20.93 & 22.94 & 20.70 & 22.70 & 24.50 & 18.37 & 19.48 & 21.21 \\
\hline 34 & 19.11 & 20.38 & 23.34 & 20.40 & 22.30 & 28.50 & 17.90 & 19.56 & 21.30 \\
\hline 35 & 19.62 & 21.75 & 24.29 & 20.90 & 22.00 & 27.00 & 18.27 & 19.83 & 23.29 \\
\hline
\end{tabular}

Note:- $\% 5$ indicates 5 th percentile; $\% 95$, 95th percentile.

Table 2: Median, 5th, and 95th percentiles for AP measurements

\begin{tabular}{|c|c|c|c|c|c|c|c|c|c|}
\hline \multirow{3}{*}{$\begin{array}{c}\text { Gestational } \\
\text { Age (wk) }\end{array}$} & \multicolumn{9}{|c|}{ Imaging Modality } \\
\hline & \multicolumn{3}{|c|}{ US 2D } & \multicolumn{3}{|c|}{ US 3D } & \multicolumn{3}{|c|}{ MRI } \\
\hline & $\% 5$ & Median & $\% 95$ & $\% 5$ & Median & $\% 95$ & $\% 5$ & Median & $\% 95$ \\
\hline 21 & 7.08 & 7.79 & 8.71 & 5.70 & 8.10 & 10.30 & & & \\
\hline 22 & 7.51 & 9.51 & 10.62 & 7.40 & 9.15 & 12.40 & & & \\
\hline 23 & 7.27 & 8.72 & 10.25 & 6.30 & 8.80 & 11.00 & & & \\
\hline 24 & 8.96 & 9.49 & 10.64 & 8.60 & 9.85 & 11.00 & & & \\
\hline 25 & 9.58 & 10.73 & 13.17 & 9.90 & 10.50 & 14.60 & & & \\
\hline 26 & 8.76 & 11.28 & 14.17 & 8.10 & 11.30 & 12.80 & & & \\
\hline 27 & 10.06 & 11.44 & 12.69 & 9.30 & 12.50 & 14.80 & 9.11 & 9.33 & 11.10 \\
\hline 28 & 10.75 & 12.32 & 14.94 & 9.20 & 12.30 & 15.90 & 8.90 & 9.97 & 12.04 \\
\hline 29 & 10.09 & 12.61 & 15.01 & 11.20 & 12.80 & 14.40 & 8.93 & 11.05 & 13.28 \\
\hline 30 & 11.06 & 13.36 & 14.94 & 10.70 & 13.70 & 16.80 & 10.39 & 11.92 & 15.01 \\
\hline 31 & 12.69 & 14.01 & 15.81 & 11.80 & 14.60 & 18.00 & 11.07 & 12.30 & 13.96 \\
\hline 32 & 11.93 & 13.87 & 17.38 & 10.70 & 15.20 & 18.40 & 11.40 & 13.04 & 13.90 \\
\hline 33 & 12.63 & 15.11 & 17.83 & 11.80 & 13.05 & 19.70 & 11.91 & 13.26 & 15.22 \\
\hline 34 & 12.36 & 15.94 & 17.82 & 12.00 & 15.60 & 21.40 & 11.18 & 13.77 & 15.10 \\
\hline 35 & 13.84 & 16.40 & 17.40 & 12.60 & 15.75 & 18.90 & 12.70 & 14.83 & 17.17 \\
\hline
\end{tabular}

Note:- $\% 5$ indicates 5 th percentile; $\% 95$, 95th percentile.

Table 3: Median, 5th, and 95th percentiles for perimeter measurements

\begin{tabular}{|c|c|c|c|c|c|c|c|c|c|}
\hline \multirow{3}{*}{$\begin{array}{c}\text { Gestational } \\
\text { Age (wk) }\end{array}$} & \multicolumn{9}{|c|}{ Imaging Modality } \\
\hline & \multicolumn{3}{|c|}{ US 2D } & \multicolumn{3}{|c|}{ US 3D } & \multicolumn{3}{|c|}{ MRI } \\
\hline & $\% 5$ & Median & $\% 95$ & $\% 5$ & Median & $\% 95$ & $\% 5$ & Median & $\% 95$ \\
\hline 21 & 36.20 & 40.94 & 44.80 & 37.20 & 41.70 & 54.60 & & & \\
\hline 22 & 37.04 & 46.80 & 48.64 & 40.60 & 47.30 & 49.40 & & & \\
\hline 23 & 41.20 & 45.07 & 49.39 & 41.50 & 46.90 & 55.20 & & & \\
\hline 24 & 48.10 & 49.89 & 51.80 & 45.00 & 49.20 & 56.70 & & & \\
\hline 25 & 46.74 & 52.41 & 62.86 & 48.80 & 53.30 & 63.30 & & & \\
\hline 26 & 50.00 & 57.87 & 65.98 & 50.80 & 58.30 & 68.60 & & & \\
\hline 27 & 48.97 & 59.08 & 67.10 & 51.40 & 64.00 & 69.30 & 50.05 & 50.67 & 57.75 \\
\hline 28 & 53.26 & 60.42 & 69.40 & 57.60 & 66.20 & 82.60 & 48.22 & 53.30 & 58.16 \\
\hline 29 & 58.58 & 65.42 & 69.37 & 58.80 & 66.40 & 77.20 & 50.58 & 56.85 & 61.09 \\
\hline 30 & 60.08 & 64.98 & 70.36 & 57.80 & 70.20 & 82.80 & 55.07 & 61.10 & 72.13 \\
\hline 31 & 61.18 & 65.67 & 71.97 & 64.10 & 71.10 & 82.40 & 59.38 & 66.21 & 71.93 \\
\hline 32 & 62.13 & 67.31 & 77.88 & 65.30 & 74.60 & 96.10 & 61.20 & 68.11 & 73.79 \\
\hline 33 & 68.13 & 71.38 & 76.83 & 73.70 & 77.95 & 82.50 & 64.98 & 70.90 & 78.33 \\
\hline 34 & 67.05 & 73.97 & 80.43 & 66.50 & 80.10 & 92.80 & 67.21 & 71.06 & 83.00 \\
\hline 35 & 70.20 & 75.19 & 79.16 & 68.50 & 79.70 & 100.20 & 69.44 & 75.93 & 86.11 \\
\hline
\end{tabular}

Note:- $\% 5$ indicates 5 th percentile; $\% 95$, 95th percentile. 
Table 4: Median, 5th, and 95th percentiles for SA measurements

\begin{tabular}{|c|c|c|c|c|c|c|c|c|c|}
\hline \multirow{3}{*}{$\begin{array}{c}\text { Gestational } \\
\text { Age (wk) }\end{array}$} & \multicolumn{9}{|c|}{ Imaging Modality } \\
\hline & \multicolumn{3}{|c|}{ US 2D } & \multicolumn{3}{|c|}{ US 3D } & \multicolumn{3}{|c|}{ MRI } \\
\hline & $\% 5$ & Median & $\% 95$ & $\% 5$ & Median & $\% 95$ & $\% 5$ & Median & $\% 95$ \\
\hline 21 & 82.41 & 99.27 & 112.76 & 70.00 & 98.00 & 126.00 & & & \\
\hline 22 & 92.43 & 114.88 & 131.10 & 95.00 & 125.00 & 141.00 & & & \\
\hline 23 & 100.38 & 125.18 & 146.12 & 92.00 & 119.00 & 164.00 & & & \\
\hline 24 & 130.89 & 138.14 & 154.26 & 118.00 & 140.50 & 175.00 & & & \\
\hline 25 & 135.91 & 170.76 & 198.12 & 127.00 & 155.00 & 233.00 & & & \\
\hline 26 & 139.84 & 189.49 & 234.09 & 150.00 & 193.00 & 215.00 & & & \\
\hline 27 & 158.35 & 198.22 & 234.51 & 176.00 & 223.00 & 255.00 & 127.08 & 143.50 & 152.34 \\
\hline 28 & 182.56 & 222.26 & 293.91 & 177.00 & 218.00 & 376.00 & 132.66 & 157.32 & 176.64 \\
\hline 29 & 215.82 & 246.64 & 293.68 & 199.00 & 235.00 & 319.00 & 140.89 & 175.90 & 204.92 \\
\hline 30 & 228.12 & 255.40 & 282.77 & 223.00 & 286.00 & 330.00 & 170.35 & 196.48 & 251.86 \\
\hline 31 & 240.25 & 268.21 & 299.06 & 219.00 & 298.00 & 355.00 & 181.44 & 214.24 & 239.03 \\
\hline 32 & 241.17 & 282.90 & 330.94 & 263.00 & 297.00 & 412.00 & 202.60 & 229.60 & 272.65 \\
\hline 33 & 274.90 & 325.12 & 370.45 & 295.00 & 308.00 & 383.00 & 207.49 & 246.18 & 266.11 \\
\hline 34 & 283.93 & 340.38 & 405.17 & 256.00 & 327.00 & 540.00 & 224.95 & 246.21 & 322.73 \\
\hline 35 & 302.87 & 350.00 & 392.47 & 280.00 & 323.00 & 478.00 & 242.75 & 279.97 & 363.32 \\
\hline
\end{tabular}

Note:- $\% 5$ indicates 5 th percentile; \%95, 95th percentile.

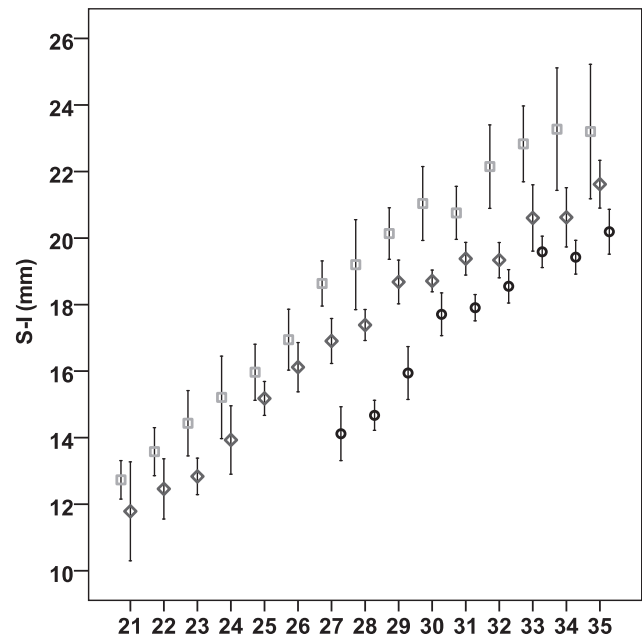

A

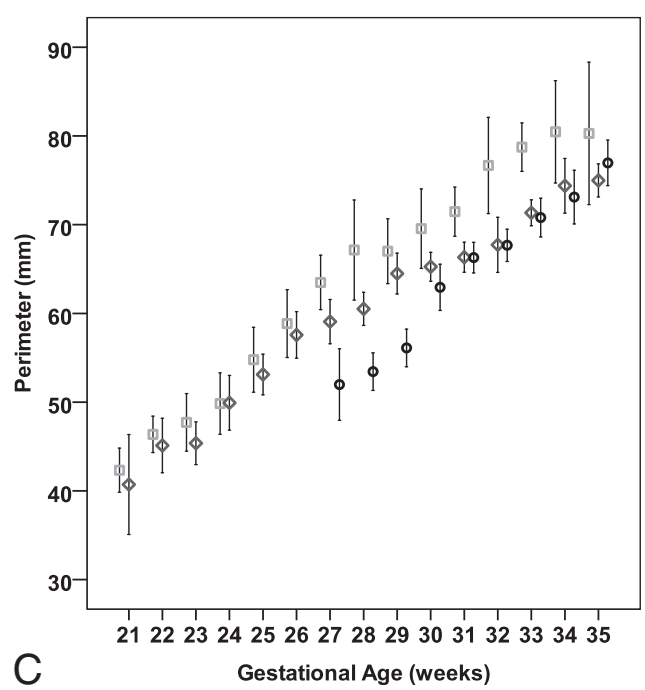

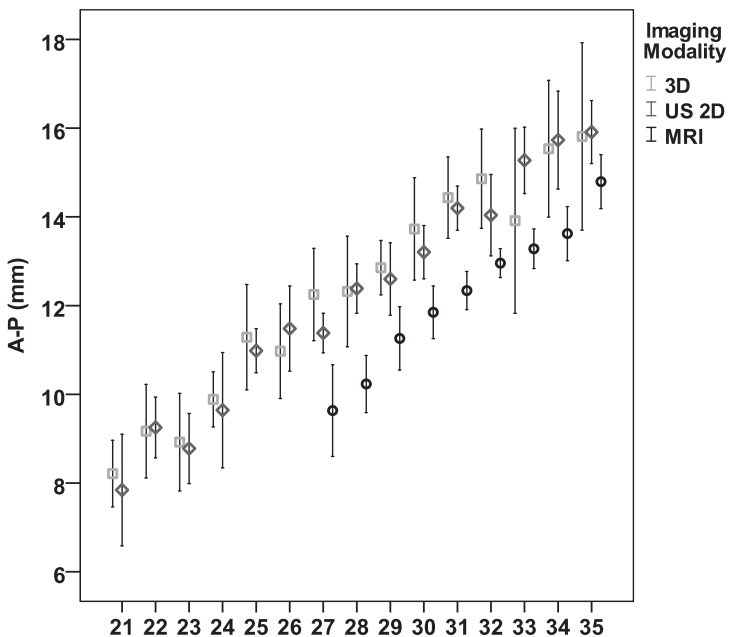

B Gestational Age (weeks)
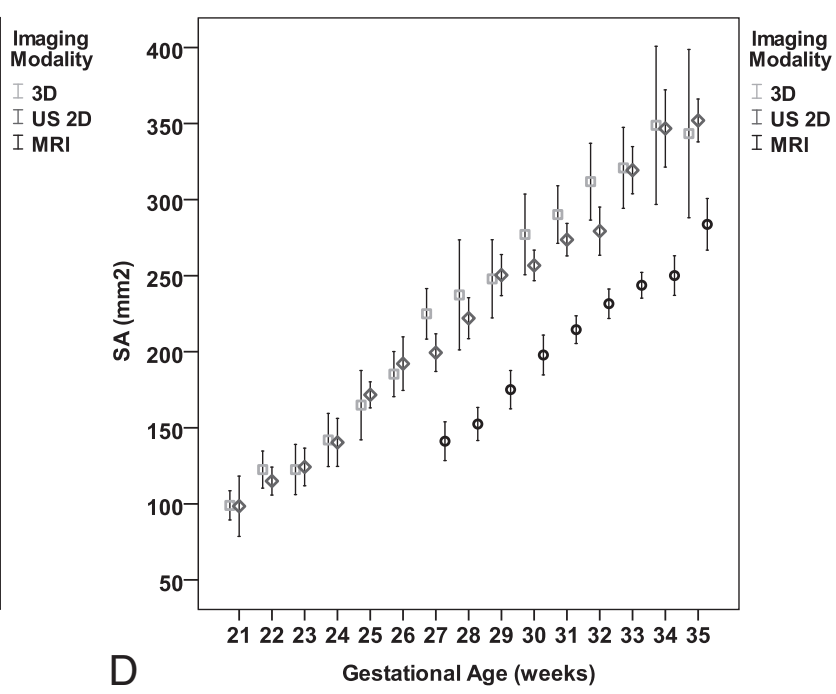

FIG 3. Comparison of measurements (mean $\pm \mathrm{SD}, 95 \% \mathrm{Cl}$ ) obtained by $2 \mathrm{D}$ US, $3 \mathrm{D}$ US, and MR imaging. A, SI. B, AP. C, Perimeter. D, SA. 
The measurements of vermian parameters were performed according to the following anatomic landmarks: 1) The maximum superoinferior (SI) diameter, the greatest height of the vermis, which is generally parallel to the axis of the brain stem;2) maximum anteroposterior (AP) diameter from the peak of the fourth ventricle, the fastigium, to the maximal AP diameter; 3 ) perimeter, the track line that follows vermian fissures; and 4) surface area, the same peripheral line that calculates surface area. All 4 parameters of the fetal vermis were measured at the same landmarks for each technique (Fig 1).

For each study group, all measurements were performed by a single operator. To evaluate the reproducibility of measurements, an arbitrary sample of 50 fetuses was evaluated twice by the first operator and then by a second operator. Each operator was unaware of the results obtained by the other.

\section{Imaging Technique and Measurements}

Sonography. All patients were scanned by using a Voluson 730 Expert or a Voluson E8 (GE Medical Systems, Kretz Ultrasound, Zipf, Austria) with a transabdominal transducer of $4-8 \mathrm{MHz}$ or a 5- to 9-MHz transvaginal probe.

2D Technique. The fetal brain was scanned in a midsagittal plane by using the transfontanel approach. A true midsagittal image of the entire vermis is defined as a plane of a section that passes

\begin{tabular}{|c|c|c|c|}
\hline & \multicolumn{2}{|c|}{ Linear Regression Coefficient } & \multirow{2}{*}{$\frac{\text { Model Summary }}{\text { Adjusted } R^{2}}$} \\
\hline & Unstandardized $\boldsymbol{\beta}^{\mathrm{a}}$ & $\overline{\text { Standardized } \beta}$ & \\
\hline \multicolumn{4}{|l|}{ SI } \\
\hline US 2D & 0.693 & 0.916 & 0.839 \\
\hline US 3D & 0.833 & 0.899 & 0.806 \\
\hline MRI & 0.742 & 0.811 & 0.656 \\
\hline \multicolumn{4}{|l|}{$\mathrm{AP}$} \\
\hline US 2D & 0.559 & 0.871 & 0.757 \\
\hline US 3D & 0.574 & 0.800 & 0.637 \\
\hline MRI & 0.606 & 0.791 & 0.624 \\
\hline \multicolumn{4}{|l|}{ Perimeter } \\
\hline US 2D & 2.340 & 0.912 & 0.831 \\
\hline US 3D & 2.989 & 0.889 & 0.790 \\
\hline MRI & 3.243 & 0.843 & 0.708 \\
\hline \multicolumn{4}{|l|}{ SA } \\
\hline US 2D & 18.487 & 0.948 & 0.897 \\
\hline US 3D & 19.670 & 0.897 & 0.804 \\
\hline MRI & 17.587 & 0.844 & 0.711 \\
\hline
\end{tabular}

a $P<.001$ for all coefficients. through the rostral and caudal convexities at the levels of the superior, middle, and inferior portion of the vermis. The fastigium should be visualized in this plane.

According to Achiron et al, ${ }^{13}$ the midsagittal view includes the corpus callosum, the cavum septi pellucidi, and the brain stemvermis plane. At the brain stem-vermis level, attention was paid to include the rostral part of the thalamus, the midbrain, the pons, the medulla oblongata, the fourth ventricle, and the cerebellar vermis (Fig 2A).

3D Technique. After a standard 2D examination, 3D volumes were acquired for off-line computer evaluation. ${ }^{10}$ Before we acquired the volume, the contrast of the $2 \mathrm{D}$ image was optimized by activating the harmonic function with high frequency, low gain, and high contrast, to enhance tissue interfaces. The $3 \mathrm{D}$ image was acquired during fetal rest in the absence of fetal movements, and the standard volume sweep angle was $55^{\circ}$. The starting image was in the axial plane at the level of the transverse cerebellar diameter. The static VCI on plane $C$ was rebuilt, and a perfect midsagittal view was obtained. Subsequently, the volume measurements were stored, and analysis was performed off-line with 4D View, Version 7.0 software (GE Healthcare, Kretz Ultrasound).

After obtaining a measurement of the volume of the fetal brain in the axial plain, we placed the reference dot in the A reference image in the middle of the vermis. Afterward, the skull was rotated along the $\mathrm{z}$-axis until the midline was horizontal, and the dot of interest was placed in the middle of the vermis in the $\mathrm{B}$ reference image. Finally, the skull was rotated again along the $\mathrm{z}$-axis until the midline was again horizontal. The image was magnified to the maximal size available, and biometric measurements were performed (Fig 2B).

MR Imaging. Scans were obtained by using a $1.5 \mathrm{~T}$ system (Optima; GE Healthcare). Single-shot fast spin-echo T2-weighted sequences in 3 orthogonal planes were performed with the following parameters: section thickness, $3 \mathrm{~mm}$; no gap; flexible coil (8channel cardiac coil); matrix, 320/224; TE, 90 ms; and TR, 1298 $\mathrm{ms}$. The FOV was determined by the size of the fetal head and was $24 \mathrm{~cm}$ for the smaller fetuses and up to $30 \mathrm{~cm}$ for the larger fetuses. T1 fast spoiled gradient-echo sequences were performed only in the axial plane with a larger FOV (400 mm); section thickness, 3 $\mathrm{mm}$; gap, $0.5 \mathrm{~mm}$; TR, $160 \mathrm{~ms}$; TE, $2.3 \mathrm{~ms}$. Then diffusionweighted sequences in the axial plane were performed with an FOV, $40 \mathrm{~cm}$; b-value, 0 and $1000 \mathrm{~ms}$; section thickness, $3 \mathrm{~mm}$; and no gap.

Table 6: Comparison of imaging modalities for each biometric measurement: estimated marginal means $95 \% \mathrm{CI}$

\begin{tabular}{|c|c|c|c|c|c|c|c|c|}
\hline & \multicolumn{2}{|r|}{ SI } & \multicolumn{2}{|r|}{ AP } & \multicolumn{2}{|c|}{ Perimeter } & \multicolumn{2}{|r|}{ SA } \\
\hline & Mean & $95 \% \mathrm{Cl}$ & Mean & $95 \% \mathrm{Cl}$ & Mean & $95 \% \mathrm{Cl}$ & Mean & $95 \% \mathrm{Cl}$ \\
\hline \multicolumn{9}{|c|}{ At gestational age $29.6 w^{a}$} \\
\hline US 2D & 18.10 & $17.91-18.30$ & 12.99 & $12.80-13.19$ & 63.34 & $62.60-64.08$ & 247.45 & $243.13-251.77$ \\
\hline US 3D & 19.80 & 19.58-20.01 & 13.18 & $12.97-13.39$ & 67.77 & $66.97-68.5$ & 258.43 & 253.77-263.10 \\
\hline MRI & 16.47 & $16.23-16.70$ & 11.40 & $11.17-11.64$ & 60.68 & $59.80-61.55$ & 181.04 & 175.90-186.1 \\
\hline \multicolumn{9}{|c|}{$\begin{array}{l}\text { For examinations preformed at } \geq 27 \mathrm{wk} \\
\text { of gestation: mean gestational age, } 31.3 \mathrm{wk}\end{array}$} \\
\hline US 2D & 19.28 & 19.05-19.51 & 13.88 & $13.64-14.11$ & 67.20 & $66.31-68.10$ & 276.99 & $271.53-282.45$ \\
\hline US 3D & 17.80 & $17.57-18.03$ & 12.36 & $12.13-12.59$ & 65.34 & $64.48-66.20$ & 212.94 & $207.68-218.20$ \\
\hline MRI & 21.34 & 21.08-21.61 & 14.20 & 13.93-14.46 & 73.28 & $72.28-74.29$ & 294.12 & $288.00-300.23$ \\
\hline
\end{tabular}

\footnotetext{
${ }^{a}$ Mean gestational age for all populations (516 fetuses).
} 
Table 7: Intraobserver reproducibility of measurements

\begin{tabular}{lcc}
\hline & \multicolumn{2}{c}{$\begin{array}{c}\text { Differences in Measurements of } \\
\text { Vermian Biometry }\end{array}$} \\
\cline { 2 - 3 } Vermian Measurement & Mean $(95 \% \mathrm{Cl}$ of the Difference) & ICC (95\% CI) \\
\hline US 2D, intraobserver variability & $-0.34 \pm 0.73(-0.54$ to -0.13$)$ & 0.94 (0.91 to 0.97$)$ \\
SI & $0.71 \pm 1.02(0.42$ to 1.00$)$ & 0.85 (0.75 to 0.91$)$ \\
AP & $0.93 \pm 2.7(0.16$ to 1.7$)$ & 0.93 (0.88 to 0.96$)$ \\
Perimeter & $2.2 \pm 14.4(2.04$ to -1.81$)$ & 0.97 (0.95 to 0.98$)$ \\
SA & & 0.95 (0.92 to 0.97$)$ \\
US 3D, interobserver variability & $-0.47 \pm 1.5(-0.89$ to -0.43$)$ & 0.98 (0.98 to 0.99$)$ \\
SI & $-0.26 \pm 0.55(-0.41$ to -0.10$)$ & 0.81 (0.7 to 0.89$)$ \\
AP & $1.05 \pm 10.66(-1.97$ to 4.08$)$ & 0.999 (0.99 to 1.0$)$ \\
Perimeter & $-1.2 \pm 2.6(-1.95$ to -0.44$)$ & 0.94 (0.91 to 0.97$)$ \\
SA & & 0.79 (0.66 to 0.88$)$ \\
MRI, intraobserver variability & $0.60 \pm 0.66(0.42$ to 0.79$)$ & 0.88 (0.81 to 0.93$)$ \\
SI & $0.55 \pm 1.05(0.25$ to 0.85$)$ & 0.97 (0.96 to 0.98$)$ \\
AP & $1.2 \pm 4.05(0.05$ to 2.3$)$ & \\
Perimeter & $-0.36 \pm 10.1(-3.2$ to 2.5$)$ & \\
SA & &
\end{tabular}

Table 8: Interobserver reproducibility of measurements

\begin{tabular}{lcc} 
& \multicolumn{2}{c}{$\begin{array}{c}\text { Differences in Measurements of } \\
\text { Vermian Biometry }\end{array}$} \\
\cline { 2 - 3 } Vermian Measurement & Mean $(95 \% \mathrm{Cl}$ of the Difference) & ICC (95\% Cl) \\
\hline US 2D, interobserver variability & $-0.07 \pm 1.15(-0.40$ to 0.25$)$ & 0.86 (0.77 to 0.92$)$ \\
SI & $0.92 \pm 1.32(0.54$ to 1.2$)$ & $0.71(0.54$ to 0.82$)$ \\
AP & $2.4 \pm 4.6(1.15$ to 3.81$)$ & $0.81(0.69$ to 0.88$)$ \\
Perimeter & $8.3 \pm 31.18(-0.47$ to 17.25$)$ & 0.86 (0.76 to 0.91$)$ \\
SA & & \\
US 3D, interobserver variability & $-0.07 \pm 1.15(-0.40$ to 0.25$)$ & $0.86(0.77$ to 0.92$)$ \\
SI & $0.92 \pm 1.32(0.54$ to 1.2$)$ & $0.71(0.54$ to 0.82$)$ \\
AP & $2.4 \pm 4.6(1.15$ to 3.81$)$ & $0.81(0.69$ to 0.88$)$ \\
Perimeter & $8.3 \pm 31.18(-0.47$ to 17.25$)$ & $0.86(0.76$ to 0.91$)$ \\
SA & & \\
MRI, interobserver variability & $-0.47 \pm 1.5(-0.89$ to -0.43$)$ & $0.95(0.92$ to 0.97$)$ \\
SI & $-0.26 \pm 0.55(-0.41$ to -0.10$)$ & $0.98(0.98$ to 0.99$)$ \\
AP & $1.05 \pm 10.66(-1.97$ to 4.08$)$ & $0.81(0.7$ to 0.89$)$ \\
Perimeter & $-1.2 \pm 2.6(-1.95$ to -0.44$)$ & 0.99 (0.99 to 1.0$)$ \\
SA &
\end{tabular}

ICC $\leq 0.2$, fair with $0.2<$ ICC $\leq 0.4$, moderate with $0.4<$ ICC $\leq 0.6$, substantial with $0.6<$ ICC $\leq 0.8$, and almost perfect with ICC $>0.8$.

\section{Ethics Approval}

The study was approved by the institutional review board of the Sheba Medical Center.

\section{RESULTS \\ Normal Biometric Reference Data}

The study groups included 516 fetuses with a normal posterior fossa: 193 in the US 2D group (range, 21-35 weeks of gestation; mean, 29.1 weeks; median, 29.5 weeks), 172 in the US 3D group (range, 21-35 weeks of gestation; mean, 28.2 weeks; median, 29.05 weeks), and 151 fetuses in the MR imaging group (range, 27-35 weeks of gestation, mean, 32.1 weeks; median, 32.6 weeks).

Biometric measurements of the vermis are described for each parameter, imaging modality, and gestational age as median and 5 th and 95th percentiles (Tables 1-4) and as mean \pm SD and $95 \%$ CI of the mean (Fig 3 and On-line Tables 1-4). For all 3 imaging

The biometric parameters of the fetal vermis were measured in the midsagittal plane by using single-shot fast spin-echo T2weighted sequences (Fig 2C).

\section{Statistical Analysis}

Statistical analysis was performed with the SPSS software, Version 22.0 (IBM, Armonk, New York). Gestational age was described as mean, median, and range. Biometric measurements of the vermis are described for each gestational age as median and 5th and 95th percentiles and as mean \pm SD and $95 \%$ CI of the mean. Linear regression models were used to assess the relationship between gestational age and vermian biometric measurements.

Comparison among the 3 imaging modalities for each biometric measurement adjusted for gestational age was performed by using a general linear model with the Bonferroni multiple comparison test. Because MR imaging was not performed before 27 weeks' gestational age, a sensitivity analysis was added considering MR imaging, US 2D, and US 3D measurements at the gestational age of $\geq 27$ weeks. Estimates of the intraclass correlation coefficient (ICC) were used to explore inter- and intra-agreement between the radiologists. Agreement was considered slight with modalities, the biometric measurements of the vermis have shown a linear growth with gestational age. Results from linear regression models are presented in Table 5.

When we compared the effect of imaging technique controlled for gestational age in the general linear model, the lowest results were those measured by MR imaging, while the highest results were measured by 3D US. All the differences (Bonferroni comparison) were significant $(P<.001)$ except AP and surface area (SA) measurements by $2 \mathrm{D}$ and $3 \mathrm{D}$ US $(P=.601$ and .02 ) (Table 6 and On-line Tables 5 and 6).

\section{Reproducibility of Measurements}

Reproducibility of measurement was excellent for all measures and all imaging modalities (Tables 7 and 8), The limits of agreement were considered acceptable for clinical purposes for all parameters, with excellent or substantial agreement defined by ICC.

\section{DISCUSSION}

The differential diagnosis of vermian pathology is quite challenging. Biometric parameters allow assessment of the integrity of the 
vermis, especially in cases in which the main anatomic landmarks cannot be well demonstrated.

This study provides vermian biometric data from a large cohort of fetuses from 21 to 35 weeks of gestation assessed by 3 imaging modalities. So far, although various nomograms have been developed by using 2D and 3D sonography and MR imaging, ${ }^{17-19}$ none has provided data regarding all 4 vermian parameters (maximum superoinferior diameter, maximum anteroposterior diameter, perimeter, and surface area) or compared measurements obtained by the 3 modalities. Moreover, it was not clear whether measurements obtained by different modalities can be compared for clinical purposes.

Biometric analysis of the vermis has a major role in the evaluation of an abnormal posterior fossa for precise prenatal diagnosis. With this study, we provide new reference data for 3 imaging modalities for the biometric parameters.

2D US is the major tool used in customary clinical work and serves as an excellent screening tool for the diagnosis of an abnormal posterior fossa. ${ }^{1}$ However, at advanced gestation, acoustic shadow from the bony fetal skull and the bony maternal pelvis make the transabdominal visualization and measurement of the vermis challenging; therefore, transvaginal US is frequently needed for clear imaging of the fetal vermis. This approach is obviously not relevant in breech presentations.

3D US imaging has 3 major advantages. The first is the ability to easily reconstruct the relevant midsagittal plane from the axial plane independent of fetal lie and position. The second is the ability to store data and perform postprocessing off-line analysis. This feature allows filter application such as static VCI to achieve improved tissue contrast and better visualization of anatomic landmarks. ${ }^{11,21}$ The third advantage is the ability to depict posterior fossa anomalies during early gestational ages. ${ }^{22}$

MR imaging has an advantage in brain imaging at advanced gestational age. Unlike 2D US and 3D US, MR imaging provides high-resolution images almost independent of maternal body habitus and fetal position. Moreover, MR imaging provides the opportunity of diagnosing associated brain abnormalities, such as migration disorders, white matter abnormalities, and so forth.

In this study for all 3 imaging modalities, the biometric measurements of the vermis have shown a linear growth with gestational age.

Statistically significant differences among imaging modalities justify applying a technique-specific reference value for fetal vermis measurements. The differences between measurements can be explained by a clearer image of the fetal vermis borders obtained by MR imaging, in comparison with the relatively blurred borders obtained by 3D US.

Reproducibility of measurements, expressed by inter- and intraobserver variability and the ICC, is not always evaluated in articles providing reference data for fetal brain measurements. ${ }^{23,24}$ Our study showed high intraobserver reproducibility (range, 0.79-0.99) and high agreement between 2 radiologists (range, 0.71-1) for all biometric measurements in the 3 imaging modalities. Similar results were reported by Tilea et $\mathrm{al}^{18}$ and by Ber et $\mathrm{al}^{25}$ for MR imaging measurements of the posterior fossa.

\section{CONCLUSIONS}

Overall, our study provides normal biometric data of the fetal vermis in a large cohort of fetuses from 21 to 35 weeks of gestation in 3 imaging modalities. Statistical analysis revealed high interand intraobserver reproducibility of measurements. Differences in biometric measurements between imaging modalities justify applying technique-specific reference values for fetal vermis measurements. The nomograms developed in this study may have a role in the multidisciplinary clinically challenging prenatal classification of an abnormal posterior fossa.

\section{ACKNOWLEDGMENTS}

The authors acknowledge Estela Derazne from the Sackler School of Medicine, Tel Aviv University, Israel, for her assistance with statistical analysis

\section{REFERENCES}

1. International Society of Ultrasound in Obstetrics \& Gynecology Education Committee. Sonographic examination of the fetal central nervous system: guidelines for performing the 'basic examination' and the 'fetal neurosonogram'. Ultrasound Obstet Gynecol 2007;29: 109-16 CrossRef Medline

2. Guibaud L, des Portes V. Plea for an anatomical approach to abnormalities of the posterior fossa in prenatal diagnosis. Ultrasound $\mathrm{Ob}$ stet Gynecol 2006;27:477-81 CrossRef Medline

3. Barkovich AJ, Millen KJ, Dobyns WB. A developmental and genetic classification for midbrain-hindbrain malformations. Brain 2009; 132:3199-230 CrossRef Medline

4. Gandolfi Colleoni G, Contro E, Carletti A, et al. Prenatal diagnosis and outcome of fetal posterior fossa fluid collections. Ultrasound Obstet Gynecol 2012;39:625-31 CrossRef Medline

5. Limperopoulos C, Robertson RL, Estroff JA, et al. Diagnosis of inferior vermian hypoplasia by fetal magnetic resonance imaging: potential pitfalls and neurodevelopmental outcome. Am J Obstet Gynecol 2006;194:1070-76 CrossRef Medline

6. Zalel Y, Gilboa Y, Gabis L, et al. Rotation of the vermis as a cause of enlarged cisterna magna on prenatal imaging. Ultrasound Obstet Gynecol 2006;27:490-93 CrossRef Medline

7. Tilea B, Delezoide AL, Khung-Savatovski S, et al. Comparison between magnetic resonance imaging and fetopathology in the evaluation of fetal posterior fossa non-cystic abnormalities. Ultrasound Obstet Gynecol 2007;29:651-59 CrossRef Medline

8. Carroll SG, Porter H, Abdel-Fattah S, et al. Correlation of prenatal ultrasound diagnosis and pathologic findings in fetal brain abnormalities. Ultrasound Obstet Gynecol 2000;16:149-53 CrossRef Medline

9. Bolduc ME, Limperopoulos C. Neurodevelopmental outcomes in children with cerebellar malformations: a systematic review. Dev Med Child Neurol 2009;51:256-67 CrossRef Medline

10. Filly RA, Cardoza JD, Goldstein RB, et al. Detection of fetal central nervous system anomalies: a practical level of effort for a routine sonogram. Radiology 1989;172:403-08 CrossRef Medline

11. Paladini D, Volpe P. Posterior fossa and vermian morphometry in the characterization of fetal cerebellar abnormalities: a prospective three-dimensional ultrasound study. Ultrasound Obstet Gynecol 2006;27:482-89 CrossRef Medline

12. Pilu G, Segata M, Ghi T, et al. Diagnosis of midline anomalies of the fetal brain with the three-dimensional median view. Ultrasound $\mathrm{Ob}$ stet Gynecol 2006;27:522-29 CrossRef Medline

13. Achiron R, Kivilevitch Z, Lipitz S, et al. The development of the human fetal pons: in utero ultrasonographic study. Ultrasound Obstet Gynecol 2004;24:506-10 CrossRef Medline

14. Malinger G, Ginath S, Lerman-Sagie T, et al. The fetal cerebellar vermis: normal development as shown by transvaginal ultrasound. Prenat Diagn 2001;21:687-92 CrossRef Medline 
15. Vinals F, Muñoz M, Naveas R, et al. The fetal cerebellar vermis: anatomy and biometric assessment using volume contrast imaging in the C-plane (VCI-C). Ultrasound Obstet Gynecol 2005;26:622-27 Medline

16. Bertucci E, Gindes L, Mazza V, et al. Vermian biometric parameters in the normal and abnormal fetal posterior fossa: three-dimensional sonographic study. J Ultrasound Med 2011;30:1403-10 Medline

17. Ginath S, Lerman-Sagie T, Haratz Krajden $\mathrm{K}$, et al. The fetal vermis, pons and brainstem: normal longitudinal development as shown by dedicated neurosonography. J Matern Fetal Neonatal Med 2013; 26:757-62 CrossRef Medline

18. Tilea B, Alberti C, Adamsbaum C, et al. Cerebral biometry in fetal magnetic resonance imaging: new reference data. Ultrasound Obstet Gynecol 2009;33:173-81 CrossRef Medline

19. Parazzini C, Righini A, Rustico M, et al. Prenatal magnetic resonance imaging: brain normal linear biometric values below 24 gestational weeks. Neuroradiology 2008;50:877-83 CrossRef Medline

20. Robinson JA, Blaser S, Toi A, et al. The fetal cerebellar vermis: assessment for abnormal development by ultrasonography and mag- netic resonance imaging. Ultrasound Q 2007;23:211-23 CrossRef Medline

21. Viñals F, Muñoz M, Naveas R, et al. Transfrontal three-dimensional visualization of midline cerebral structures. Ultrasound Obstet $G y$ necol 2007;30:162-68 Medline

22. Garcia-Flores J, Recio M, Uriel M, et al. Fetal magnetic resonance imaging and neurosonography in congenital neurological anomalies: supplementary diagnostic and postnatal prognostic value. J Matern Fetal Neonatal Med 2013;26:1517-23 CrossRef Medline

23. Chitty LS, Altman DG, Henderson A, et al. Charts of fetal size, 2: head measurements. Br J Obstet Gynaecol 1994;101:35-43 CrossRef Medline

24. Kurmanavicius J, Wright EM, Royston $\mathrm{P}$, et al. Fetal ultrasound biometry: 1. Head reference values. Br J Obstet Gynaecol 1999;106: 126-35 CrossRef Medline

25. Ber R, Bar-Yosef O, Hoffmann C, et al. Normal fetal posterior fossa in MR imaging: new biometric data and possible clinical significance. AJNR Am J Neuroradiol 2015;36:795-802 CrossRef Medline 